\title{
Mitochondrial oxidative activity in human rheumatoid synovial lining cells
}

\author{
B. HENDERSON, L. BITENSKY, AND J. CHAYEN
}

From the Division of Cellular Biology, Kennedy Institute of Rheumatology, Bute Gardens, London W6 7DW0

SUMMARY The activities of two mitochondrial enzymes, succinate dehydrogenase and cytochrome oxidase, have been measured by quantitative cytochemistry and microdensitometry in the synovio-@ cytes of rheumatoid and non-rheumatoid synovial lining cells. Although both tended to be higher in the former, there was no statistically significant difference in the activities of either enzyme in these tissues. However, when cytochrome oxidase activity was measured without exogenous cytochrome cion the activity in the rheumatoid synoviocytes was highly significantly elevated. It is suggested that theseo findings may indicate only that the cytochrome c-cytochrome oxidase complex in the rheumatoid? cells is more stable, possibly because of the increased availability of phospholipids in these cells.

Such studies as have been done on oxidative carbohydrate metabolism of human synoviocytes from rheumatoid synovial tissue have concentrated rather on the glycolytic, Embden-Meyerhof pathway. Using manometric methods on specimens of synovial tissue, both Dingle and Page Thomas (1956) and Roberts et al. (1967) found increased activity of this pathway in rheumatoid tissues. In such studies the increased cellularity of rheumatoid synovial tissue may account for the increased glycolytic activity. However, by means of quantitative cytochemistry, which allows measurement of the activity in the synoviocytes free from contributions from infiltrating cells, Henderson (1977) showed increases in the activity of some of the enzymes of the glycolytic pathway. Thus it seems likely that glycolytic activity is enhanced in rheumatoid synoviocytes and this raised the question of whether mitochondrial activity was similarly increased to meet the increased glycolytic flux. Very little work has been done on this question. It was therefore decided to examine the activity of two key mitochondrial oxidative enzymes: succinate dehydrogenase, which is the most active of the Krebs' cycle enzymes, and cytochrome oxidase, which is the terminal acceptor of the respiratory chain. Previous work by Butcher (1970) had validated the cytochemical measurement of these enyzmes.

Accepted for publication January 9, 1978

Correspondence to J. Chayen, Division of Cellular Biology, Kennedy Institute of Rheumatology, Bute Gardens, London W6 7DW.

\section{Materials and methods}

Non-rheumatoid specimens were taken from the knẹ during routine arthrotomy for internal derangementis. They came either from quiescent joints or frip otherwise normal joints following recent mechanicak trauma. The rheumatoid specimens were taken $\overrightarrow{5}$ mainly from the knee during the course of syno vectomy; all the patients from whom the rheumatoid synovium was taken had 'definite' or 'classical disease according to the diagnostic criteria of the American Rheumatism Association (Ropes et al.? 1959). All specimens were taken in a bloodless fieldo but within $10 \mathrm{~min}$ of the application of the tourniquet Pieces of such tissues approximately $4 \mathrm{~mm}^{3}$ weres chilled by precipitate immersion in $n$-hexane (BDH 'free from aromatic hydrocarbons' grade boiling range $67-70^{\circ} \mathrm{C}$ ). After no longer than 1 mino the specimens were removed from the hexane and stored at $-70^{\circ} \mathrm{C}$ in corked dry glass tubes. Theys were then sectioned at $10 \mu \mathrm{m}$ in a Bright's cryostat maintained at a cabinet temperature of -25 to $-30^{\circ} \mathrm{C}$ with the knife cooled to $-70^{\circ} \mathrm{C}$ by havings solid carbon dioxide packed around its haft. The sections were flash-dried on to slides (Chayen et al. .0 1973). For each specimen several sections were stainedw with toluidine blue to establish the precise histology일

Succinate dehydrogenase activity (E.C. 1.3.99.1\% was measured by the procedure of Butcher (1970) The reaction involves the oxidation of succinate in the presence of the intermediate hydrogen=0 acceptor, phenazine methosulphate (PMS) whicl? 
accepts reducing equivalents from the flavoprotein of the dehydrogenase (Slater, 1961) which are then transferred quantitatively to neotetrazolium chloride (obtained from Merck $\mathrm{GmbH}$, and purified by extraction with chloroform before use). The reduced neotetrazolium salt is a strongly coloured formazan which was measured specifically in synoviocytes at $585 \mathrm{~nm}$ by the use of a Vickers M85 scanning and integrating microdensitometer. The stoicheiometry of the production of the formazan has been determined by Butcher and Altman (1973).

Cytochrome oxidase (E.C. 1.9.3.1) activity was measured by the method of Butcher et al. (1964). The activity of this enzyme in this reaction depends on the endogenous concentration of oxidised cytochrome c. Normally the reaction is done without exogenous cytochrome c; to demonstrate the maximal activity, sections were reacted in the normal medium reinforced with $10^{-4} \mathrm{~mol} / 1$ cytochrome c (Sigma). The reaction product is an indophenol produced by the reaction between $\mathrm{N}$-phenyl-p-phenylene diamine, 1-hydroxy-2-naphthoic acid and oxidised cytochrome $\mathrm{c}$; the cytochrome is then re-oxidised by cytochrome oxidase. This forms an insoluble reactionproduct which was measured in synovial lining cells at $550 \mathrm{~nm}$. As controls, serial sections were reacted in the same reaction medium containing potassium cyanide $\left(10^{-3} \mathrm{~mol} / \mathrm{l}\right)$.

For each reaction, 15-20 fields, each containing 2-3 synovial lining cells, were measured in each of duplicate or triplicate sections ( $\times 40$ objective; scanning spot of area $0.5 \mu \mathrm{m}$ diameter). The integrated relative absorption per unit field, recorded by the microdensitometer, was converted to units of absolute integrated extinction (IE) per unit field by suitable calibration. The significance of the results was evaluated by Student's $t$ test.

\section{Results}

\section{CYTOCHROME OXIDASE ACTIVITY}

\section{IN SYNOVIOCYTES}

The direct activity of cytochrome oxidase in these cells, that is without the addition of exogenous cytochrome c, was measured in the synovial lining cells of 16 specimens of non-rheumatoid and 15 specimens of rheumatoid synovial tissue. The small residual 'activity' found in the presence of cyanide was subtracted from the activity recorded without $K C N$. The activity in the non-rheumatoid specimens was $2 \pm 0.61$ (mean \pm standard error) whereas that in the rheumatoid cells was $18 \pm 5 \cdot 71$. The difference was highly significant $(P<0.001)$.

The maximal cytochrome oxidase activity was measured in the synoviocytes in 7 samples of nonrheumatoid and 8 of rheumatoid synovial tissue
Table 1 The effect of exogenous cytochrome c (cyt c) on cytochrome oxidase activity in synovial lining cells (after subtraction of $K C N$ insensitive activity).

\begin{tabular}{|c|c|c|c|}
\hline \multirow[t]{2}{*}{ Tissue } & \multirow[t]{2}{*}{ Case No. } & \multicolumn{2}{|c|}{ Activity $\left(I E \times 10^{3} / 10 \mathrm{~min}\right)$} \\
\hline & & No cyt c & Plus cyt c \\
\hline Mean (and standar & $\begin{array}{l}1665 \\
1824 \\
1877 \\
1916 \\
1935 \\
1982 \\
1989 \\
\text { error) }\end{array}$ & $\begin{array}{l}1 \\
1 \\
0.5 \\
5 \\
3 \\
2 \\
3 \\
2(0.61)\end{array}$ & $\begin{array}{l}26 \\
8 \cdot 5 \\
6 \\
5 \cdot 5 \\
21 \\
7 \cdot 5 \\
6 \cdot 5 \\
11 \cdot 5(3 \cdot 26)\end{array}$ \\
\hline Mean (and standar & $\begin{array}{l}1815 \\
1819 \\
1854 \\
1911 \\
1928 \\
1941 \\
1946 \\
1980 \\
\text { error) }\end{array}$ & $\begin{array}{l}16 \cdot 5 \\
16 \\
3 \cdot 5 \\
8 \cdot 5 \\
48 \\
13 \\
18 \\
- \\
18(5 \cdot 71)\end{array}$ & $\begin{array}{l}26 \\
40 \\
9 \\
20 \cdot 5 \\
37 \\
17 \\
17 \cdot 5 \\
21 \\
24(3 \cdot 96)\end{array}$ \\
\hline
\end{tabular}

No significant difference in activity in presence of exogenous cytochrome c $(0.5>P>0.25)$.

(Table 1). Although the difference in activity without added cytochrome $c$ remained significant, the activities in the presence of added cytochrome $c$ were not significantly different $(0.5>P>0.25)$. At best, the rheumatoid specimens showed twice the maximal activity shown by the non-rheumatoid with considerable overlap of activities.

\section{SUCCINATE DEHYDROGENASE ACTIVITY}

The activity of this enzyme has been measured in the synoviocytes of 9 specimens of non-rheumatoid and 11 specimens of rheumatoid synovial tissue. As with the total cytochrome oxidase activity, the succinate dehydrogenase activity in the rheumatoid specimens tended to be higher and the overall mean activity was nearly twice that in the non-rheumatoid specimens. However, there was considerable overlap of activities (Table 2) and the results were not statistically significant.

\section{Discussion}

Previous biochemical studies (Dingle and Page Thomas, 1956; Roberts et al., 1967) and cytochemical investigations (Henderson, 1977) indicated that rheumatoid synoviocytes had elevated glycolytic activity. The activity of the hexose monophosphate pathway has also been shown to be considerably increased in rheumatoid synovial lining cells (Butcher et al., 1973; Henderson, 1977). Thus it seems likely that there is an increased rate of carbohydrate metabolism in rheumatoid synoviocytes. The question was whether or not this was matched by increased mitochondrial oxidative activity. 
Table 2 Succinate dehydrogenase activity $\left(I E \times 10^{3} / 10 \mathrm{~min}\right)$ in synovial lining cells

\begin{tabular}{|c|c|c|c|}
\hline \multicolumn{2}{|c|}{ Non-rheumatoid } & \multicolumn{2}{|c|}{ Rheumatoid } \\
\hline Case No. & Activity & Case No. & Activity \\
\hline $\begin{array}{l}1652 \\
1655 \\
1665 \\
1712 \\
1717 \\
1877 \\
1883 \\
1916 \\
1935\end{array}$ & $\begin{array}{r}36 \\
33 \\
73 \\
16 \\
6 \\
25 \\
7 \\
2 \\
51\end{array}$ & $\begin{array}{l}1677 \\
1681 \\
1692 \\
1696 \\
1709 \\
1711 \\
1722 \\
1815 \\
1819 \\
1911 \\
1928\end{array}$ & $\begin{array}{l}23 \\
20 \\
82 \\
74 \\
33 \\
98 \\
26 \\
81 \\
26 \\
37 \\
44\end{array}$ \\
\hline
\end{tabular}

Mean (and standard error)

$$
28(8 \cdot 13)
$$

$49(8 \cdot 36)$

Difference in activity between non-rheumatoid and rheumatoid lining cells not significant.

The present investigation concentrated on two mitochondrial enzymes. The first, cytochrome oxidase, is the terminal enzyme of the mitochondrial electron-transport chain that is responsible for the production of ATP by mitochondrial oxidative phosphorylation. Lemberg and Barret (1973) showed that there is close agreement between the cytochrome oxidase content of a tissue and its oxygen utilisation. Thus the measurement of the maximal cytochrome oxidase activity (assayed in the presence of added cytochrome c) should give an indication of the oxygen consumption of the lining cells. The second enzyme studied was succinate dehydrogenase which is the most active of the tricarboxylic acid cycle (Lehninger, 1975). Mitochondrial membranes are said to be freely permeable to its substrate (Chappell, 1968). Thus the activity recorded in this study should represent the maximal activity of the tricarboxylic acid cycle in the synoviocytes.

Although there was some suggestion of elevated levels of succinate dehydrogenase and maximal cytochrome oxidase in the rheumatoid synoviocytes, there was such overlap of values that the results were not statistically significantly different. This contrasts with the marked changes in glucose 6-phosphate dehydrogenase activity recorded by Butcher et al. (1973) and by Henderson (1977) who obtained values of $70 \pm 48$ (mean integrated extinction $\times 10^{3} /$ unit field/10 $\mathrm{min}$ ) in non-rheumatoid as against $499 \pm 217$ in rheumatoid synoviocytes. Henderson (1977) also found a marked increase in lactate dehydrogenase activity in rheumatoid synovial lining cells $(652 \pm 316$ as against $156 \pm 77$ in nonrheumatoid cells).

Although there was no significant difference in the maximal cytochrome oxidase activity between rheumatoid and non-rheumatoid synoviocytes, the level of activity found in the absence of added cyto chrome $\mathrm{c}$ was markedly and significantly different Cytochrome $\mathrm{c}$ is a soluble molecule which is easils removed from mitochondria (Lemberg and Barre 1973). It is also readily lost from unfixed cryostat sections such as those used in this study (Roels: 1974). It is known that cytochrome c binds to cytochrome oxidase, the degree of binding bein dependent on phospholipid concentration, so that binding is increased parallel to an increase io phospholipid concentration (Tzagoloff and Maङ Lennan, 1965). Recent studies have revealed an increase in the available (unbound or unmasked phospholipids in human rheumatoid synoviocyte (Henderson et al., 1978). It is therefore possible that the increased activity of cytochrome oxidase (testee without added cytochrome c) in rheumatoid synoo viocytes is due to the greater binding of cytochrom c to cytochrome oxidase as a result of the increased concentration of unbound phospholipids. Suct phospholipids could interact with the cytochrom $\vec{e}$ c-cytochrome oxidase complex to increase the binding of cytochrome $\mathrm{c}$ and prevent solubilisation of thes molecule. Conversely, in the non-rheumatoid cels the cytochrome $\mathrm{c}$ would be less tightly bound and more easily solubilised into the reaction-mediump $\overrightarrow{0}$

Thus these results imply that the increased araib ability of phospholipids in rheumatoid synoviocffes (Henderson et al., 1978) may assist the binding] cytochrome $c$ and the stability of the cytochrome c-cytochrome oxidase complex, so enhancing the capability of rheumatoid mitochondria. They show that, despite some enhanced glycolysis, and core siderable elevation of the hexose monophosphat $\overrightarrow{0}$ pathway, there may be no great difference in the potential mitochondrial oxidative activity associate with the rheumatoid condition.

We are grateful to Mr B. Cashman, FRCS and MP A. Catterall, FRCS for their interest in this work and for supplying the specimens. We are glad to acknowledge a grant towards this work from the Medical Research Council, and the support of the Arthritis and Rheumatism Council for Research.

\section{References}

Butcher, R. G. (1970). Studies on succinate oxidation. I. The use of intact tissue sections. Experimental Cell Researchs 60, 54-60.

Butcher, R. G., and Altman, F. P. (1973). Studies on thro reduction of tetrazolium salts. II. The measurement of the half-reduced and fully reduced formazans of neotetras zolium chloride in tissue sections. Histochemie, 37, 35 363.

Butcher, R. G., Bitensky, L., Cashman, B., and Chayen, f? (1973). Differences in the redox balance in human rheut matoid and non-rheumatoid synovial lining cells. Beiträgతe zur Pathologie, 148, 265-274. 
Butcher, R. G., Diengdoh, J. V., and Chayen, J. (1964). A study of the histo-chemical demonstration of cytochrome oxidase. Quarterly Journal of Microscopial Science, 105, 497-504.

Chappell, J. B. (1968). Systems used for the transport of substrates into mitochondria. British Medical Bulletin, 24, 150-157.

Chayen, J., Bitensky, L., and Butcher, R. G. (1973). Practical Histochemistry. Wiley: London.

Dingle, J. T., and Page Thomas, D. P. (1956). In vitro studies on human synovial membrane. A metabolic comparison of normal and rheumatoid tissue British Journal of Experimental Pathology, 37, 318-323.

Henderson, B. (1977). Quantitative Cytochemical Studies of Rheumatoid Arthritis. PhD Thesis, Brunel University.

Henderson, B., Bitensky, L., and Chayen, J. (1978). Altered phospholipids in human synovial lining cells. Annals of the Rheumatic Diseases, 37, 24-29.

Lehninger, A. L. (1975). Biochemistry. Worth: New York.
Lemberg, R., and Barret, J. (1973). Cytochromes. Academic Press: New York and London.

Roberts, J. E., McLees, B. D., and Kerby, G. P. (1967). Pathways of glucose metabolism in rheumatoid and nonrheumatoid synovial membrane. Journal of Laboratory and Clinical Medicine, 70, 503-511.

Roels, F. (1974). Cytochrome c and cytochrome oxidase in diaminobenzidine staining of mitochondria. Journal of Histochemistry and Cytochemistry, 22, 442-444.

Ropes, M. W., Bennet, G. A., Cobb, S., Jacox, R., and Jessar, R. A. (1959). Diagnostic criteria for rheumatoid arthritis. Annals of the Rheumatic Diseases, 18, 49-53.

Slater, E. C. (1961). Succinic dehydrogenase. In Biochemists' Handbook, edited by C. Long, pp. 369-371. Spon: London.

Tzagoloff, A., and MacLennan, D. H. (1965). Studies of the electron transfer system. LXIV. Role of phospholipid in cytochrome oxidase. Biochimica et Biophysica Acta, 99, 476-485. 